\title{
Research on Nexus among Urbanization, Economic Growth and Energy Consumption in Shanghai"
}

\author{
Pinjie Xie, Quansheng Shi and Jianchao Hou \\ School of Economics and Management Shanghai University of Electric Power, Shanghai, China \\ yjzxpj@163.com, shiqs@126.com, hdshuoyu@126.com
}

\begin{abstract}
Using the time serial data of Shanghai from 19782010 , this paper studies the long-term equilibrium relationship, shortterm dynamic relationship and Granger causality among Shanghai's urbanization, economic growth and the energy consumption. The results indicate that urbanization, economic growth and energy consumption are co-integrated and that in the long-run Shanghai's urbanization and energy consumption Granger cause economic development, and Granger reason running from urbanization to energy consumption and from economic development to urbanization, and that in the short-run there is bi-directional Granger causality between Shanghai's urbanization and energy consumption.

Index Terms - Energy consumption, Urbanization, Economic growth, Causality, Cointegration.
\end{abstract}

\section{I . Introduction}

The energy consumption is rising sharply with the rapid development of economy and the acceleration of urbanization in Shanghai City. The total quantity of energy consumption in Shanghai City was $54,994,800$ tons of standard coal in 2000, and it increased to $111,608,700$ tons of standard coal in 2010 . Shanghai's energy is extremely scarce, taking the year 2010 as an example, the primary energy output of Shanghai City is only 723,900 tons of standard coal, and the vast majority of the required energy relies on the transfer from other provinces or the importation from other countries. It can be predicted that the economic growth and the further acceleration of urbanization in Shanghai City would inevitably lead to the sharp rise of its energy consumption, and the imbalanced state between energy supply and demand would be even more serious. Such restrictions on the energy input caused by the imbalance of supply and demand would inevitably affect the rate of economic growth and the progression of urbanization in Shanghai City. Therefore, the relationship among energy consumption, economic development and urbanization is studied by combining the situation of economic development and the progression of urbanization in Shanghai City, and the growth trend of energy demand is grasped on the basis of the study, so as to provide a scientific decision-making basis for relevant government departments, which has great significance for both the long-term planning of Shanghai's economy and the strategy making of energy development. Therefore, Shanghai City is taken as an example in this paper, according to the relevant annual data during 1978-2010, quantitative analysis on the relationship among urbanization, economic growth and energy consumption is carried out by applying the vector regression model (VAR) and the vector error correction model (VECM), and some relevant policy suggestions are proposed on the basis of empirical basis.

\section{II . Literature review}

Since the 1970s, the analysis on the relationship between energy consumption and economic growth has been an important research field for economic circles at home and abroad, its main focus is to examine the long-term equilibrium relationship, the short-term dynamic adjustment and the causality relationship between energy consumption and GDP by using various quantitative methods, especially cointegration and VECM model, thus to predict the future energy demand and the elasticity of demand. For example, Jumbe (2004) studied the co-integration relationship between the electricity consumption during 1970-1999 and GDP and the non-farm GDP in Malawi by using Johansen co-integration test, and analyzed their causality by applying the Granger bivariate causality test of VECM model[1]; Paresh and Russel (2005) tested the causality between the electricity consumption during 1966-1999 in Australia and the economic development by applying VECM and result mutation analysis, and predicted the future electricity demand behavior[2].

In the aspect of the study on the relationship between the energy demand and the economic growth in China, Boqiang Lin(2003) studied the relationship between the electricity consumption and the economic growth in China by applying co-integration analysis and VCEM model under the production function framework of the three elements[3]; Zhongfu Tan (2008) analyzed the timing of the external impact's structural mutation on the relationship between energy demand and GDP in China, and established the term model of China's energy by applying co-integration introduction and error correction model on the basis of the above analysis[4]. In addition, with the rapid development of the urbanization level of China, the study on the relationship between energy consumption and urbanization has gradually become a hot spot. Yaobin Liu(2007) analyzed the relationship between the urbanization and the energy consumption during 1978-2005 in China on the basis of vector auto-regression model, and also quantitatively calculated the contribution shares of urbanization on the energy consumption in China by using factorization model[5].

\footnotetext{
* This work is supported by the National Natural Science Foundation of China NSFC Grants \#71103120, MOE (Ministry of Education in China) Project of Humanities and Social Sciences Grants \#10YJC790299, and Innovation Program of Shanghai Municipal Education Commission Grants \#11YS201 to P.J. Xie.
} 
Xiaoping $\mathrm{He}(2009)$ conducted a comparative study and prediction on the electricity demand in the urbanization progress of China by applying panel data nonlinear model and co-integration model respectively[6]; Pinjie Xie(2009) analyzed the interactional dynamic relationship between the urbanization and the electricity consumption level in China since China's reform and opening-up in both long term and short term[7].

But comparatively speaking, the current researches on the influence effect of urbanization on the energy consumption are still weak, and the relationship between the two elements needs to be further studied. In addition, no paper has ever conducted a study on the combination of energy consumption, economic growth and urbanization. Therefore, this paper conducts an empirical study on the co-integration relationship and causality among the urbanization, the economic growth and the energy consumption during 1978-2010 in Shanghai City, so as to provide a reference for the achievement of economic society's sustainable development in the progression of Shanghai's urbanization.

\section{Data and Econometric Methodology}

\section{A. Data}

Energy consumption, economic growth and urbanization are studied under the same framework by applying multivariate analysis, and their relationship can be expressed as the following model:

$$
E_{t}=f\left(Y_{t}, U_{t}\right)
$$

In the formula, $E_{t}$ is energy consumption, it is measured by the total energy consumption of the whole society, and the unit is 10,000 tons of standard coal; $Y_{t}$ is variable of economic growth, it is measured by GDP and adjusted by the GDP index that has 1978 as the base period, and the unit is 100 million Yuan; $U_{t}$ is urbanization level, it is measured by "the proportion of the urbanization population in total population" of Shanghai City, and the unit is \%. The above data are all from "Shanghai Statistical Yearbook Year 2011". As the adoption of natural logarithm from the variables won't change the co-integration relationship between them and also can eliminate the heteroscedasticity that may exist in the raw data, therefore, natural logarithm processing is conducted on the data of above three variables, and they are recorded as $\ln E, \ln Y$ and $\ln U$ respectively.

\section{B. Econometric Methodology}

The purpose of the empirical research in this paper is to test the causality among the variables, and there are three main steps: the first step is to conduct unit root test on the variables and test the stationarity of each variable; the second step is to test the co-integration relationship among the variables and also test whether there is long-term equilibrium relationship among the variables; the third step is to correct the model on the basis of vector error and test the causality among the variables.

Assuming that there is only one co-integration relationship, the error correction model of multi-variables is as follows:

$$
(1-L)\left[\begin{array}{l}
\ln E_{t} \\
\ln Y_{t} \\
\ln U_{t}
\end{array}\right]=\left[\begin{array}{c}
\alpha_{1} \\
\alpha_{2} \\
\alpha_{3}
\end{array}\right]+\sum_{i=1}^{p}(1-L)\left[\begin{array}{lll}
\beta_{11 i} & \beta_{12 i} & \beta_{13 i} \\
\beta_{21 i} & \beta_{22 i} & \beta_{23 i} \\
\beta_{31 i} & \beta_{32 i} & \beta_{33 i}
\end{array}\right]\left[\begin{array}{l}
\ln E_{t-i} \\
\ln Y_{t-i} \\
\ln U_{t-i}
\end{array}\right]+\left[\begin{array}{l}
\theta \\
\vartheta \\
\varphi
\end{array}\right]\left[E C M_{t-1}\right]+\left[\begin{array}{c}
\varepsilon_{1 t} \\
\varepsilon_{2 t} \\
\varepsilon_{3 t}
\end{array}\right]
$$

Among which: $L$ is the lag operator, so $(1-L)$ is the firstorder difference taken from relevant variables; $\alpha_{i}(i=1,2,3)$ is constant term; $\varepsilon_{i t}(i=1,2,3)$ is the stable white noise sequence; $E C M_{t-1}$ is error correction term, that is the residual of standardized co-integration equation.

The vector error correction model can test short-term Granger causality, long-term Granger causality (weakly exogenous test) and strong Granger causality (long-term / short-term joint test). For example, the judgment on whether $\Delta \ln Y_{t}$ can cause $\Delta \ln E_{t}$ in the short term is made through testing whether the lagged variable's parameter $\beta_{12 i}$ of $\Delta \ln Y_{t}$ is significant, its null hypothesis is $\mathrm{H}_{0}: \beta_{121}=\ldots=\beta_{12 p}=0$, if the null hypothesis is rejected, short-term Granger causality from $\Delta \ln Y_{t}$ to $\Delta \ln E_{t}$ would exist. Furthermore, if the test rejects the null hypothesis $\mathrm{H}_{0}: \theta=\beta_{121}=\ldots=\beta_{12 p}=0$, the long-term Granger causality from $\Delta \ln Y_{t}$ to $\Delta \ln E_{t}$ would exist.

\section{IV . Empirical results}

\section{A. Unit Root Tests Results}

In the quantitative analysis, in order to prevent the spurious regression generated from the unstable macroeconomic variables, ADF test on the time sequence needs to be carried out at first place. In this paper, ADF test and PP test are applied to determine the stationarity of the variables. Combined with the graphics of each variable, it can be found that each level variable is qualified with relatively obvious trend, therefore, in the specific inspection process, test equations of level variables all have intercept and trend term while the test equations of difference sequence only contain intercept. The test results are shown in Table I. By considering the results of ADF test and PP test as a whole, it can be seen that the variable sequences involved in this paper are integrated of order one $I(1)$ sequence.

TABLE I Unit Root Test Results

\begin{tabular}{|c|c|c|c|c|}
\hline \multirow{2}{*}{ Variable } & \multicolumn{2}{|c|}{ ADF test } & \multicolumn{2}{c|}{ PP test } \\
\cline { 2 - 5 } & ADF statistic & Prob. & PP statistic & Prob. \\
\hline $\ln E$ & $-2.4339(1)$ & 0.3562 & $-2.3955[1]$ & 0.3748 \\
\hline $\ln Y$ & $-2.1321(1)$ & 0.5087 & $-1.8291[1]$ & 0.6669 \\
\hline $\ln U$ & $-2.4668(1)$ & 0.3410 & $-0.9436[0]$ & 0.9380 \\
\hline$\Delta \ln E$ & $-3.0541(0)$ & 0.0409 & $-2.9010[4]$ & 0.0567 \\
\hline$\Delta \ln Y$ & $-2.9508(0)$ & 0.0510 & $-2.9508[0]$ & 0.0510 \\
\hline$\Delta \ln E$ & $-3.3194(1)$ & 0.0228 & $-3.6622[1]$ & 0.0100 \\
\hline
\end{tabular}

Note: $\Delta$ denotes first difference; Numbers in parentheses are lag levels determined via the Akaike Information Criterion (AIC). Numbers in brackets represents the automatic Newey-West bandwidth selection using the Bartlett kernel.

\section{B. Cointegration Test Results}

In this paper, the regression coefficient based Johansen co-integration test method is applied to analyze the co- 
integration relationship among urbanization, economic growth and energy consumption, which specifically include Trace test method and Max-Eigen test method specifically. As this method is conducted according to VAR model, the lag order of VAR model needs to be determined firstly before the cointegration test. The test results show that the application of LR, FPE, AIC and HQ indicates that the optimal lag order is 5. Based on VAR(5), the specific results of Johansen cointegration test are given, and they are shown in Table II. Among which, the trend hypothesis is that both sequence and co-integration equation have linear trend.

TABLE II Results of Cointegration Test Results for $(\ln E, \ln Y, \ln U)$

\begin{tabular}{|c|c|c|c|c|}
\hline \multirow{2}{*}{$\mathrm{H}_{0}$} & \multicolumn{2}{|c|}{ Trace test } & \multicolumn{2}{c|}{ Max-Eigentest } \\
\cline { 2 - 5 } & Statistic & Prob. & Statistic & Prob. \\
\hline None & 142.2143 & 0.0000 & 70.03111 & 0.0000 \\
\hline At most 1 & 72.18318 & 0.0000 & 54.58329 & 0.0000 \\
\hline At most 2 & 17.59989 & 0.0065 & 17.59989 & 0.0065 \\
\hline
\end{tabular}

As shown in Table II, both tests suggest the existence of cointegration vector among the variables at the 0.05 level, that is, there is a kind of long-run equilibrium relationship between them. The estimation results are given below:

$$
\begin{gathered}
\ln E=2.1007+0.1896 \ln U+0.88501 \ln Y-0.04482 \text { trend } \\
(0.29332) \quad(0.08449) \quad(0.00736)
\end{gathered}
$$

The figure in the parentheses of Formula (3) is the standard deviation of coefficient. It can be obtained that there is a longterm stable equilibrium relationship among the energy consumption, the economic growth and the urbanization level in Shanghai City. And from the aspect of growth stage, the elasticity coefficients of Shanghai's urbanization level and economic growth to the energy consumption level are respectively 0.1896 and 0.8850 since China's reform and opening-up. The above estimated results show that although urbanization and economic growth have significant positive effects on Shanghai's energy consumption quantity, their driving effects are not the same. Specifically, when the urbanization level and GDP of Shanghai City increase by $1 \%$, the energy consumption level would correspondingly increase by $0.1896 \%$ and $0.8850 \%$.

\section{Error Correction Model}

As there is a long-term equilibrium relationship among energy consumption, urbanization level and economic growth in Shanghai City, the short-term dynamic correlation among these three elements can be analyzed through establishing error correction model according to Granger representation theorem. Considering that the lag phase of error correction model is the lag phase of the first order difference variable of the unconstrained VAR model, and the optimal lag phase of the unconstrained VAR model that has been determined in the above part of paper is 5, therefore, the corresponding lag phase of error correction model adopts 4 . Then, according to the inspection criteria which is from the general to the special, gradually eliminating the explanatory variables whose $t$ statistic hasn't pass the $10 \%$ of significant level, and the following findings are respectively obtained are shown in Table III.

\begin{tabular}{|c|c|c|c|}
\hline \multirow{2}{*}{$\begin{array}{l}\text { Explanatory } \\
\text { Variable }\end{array}$} & \multicolumn{3}{|c|}{ Dependent Variable } \\
\hline & $\triangle \ln E$ & $\triangle \ln Y$ & $\triangle \ln U$ \\
\hline$C$ & $0.0466(4.052)$ & $0.0734(4.413)$ & \\
\hline$E C M_{t-1}$ & & $0.3425(5.007)$ & $-0.0408(-1.794)$ \\
\hline$\triangle \ln E_{t-1}$ & $0.3938(2.352)$ & & $0.1283(1.805)$ \\
\hline$\triangle \ln E_{t-3}$ & & $-0.3884(-1.916)$ & \\
\hline$\triangle \ln E_{t-4}$ & & $-0.6715(-3.267)$ & $0.1662(2.160)$ \\
\hline$\triangle \ln Y_{t-1}$ & & $0.5441(4.131)$ & $0.1211(2.694)$ \\
\hline$\triangle \ln Y_{t-2}$ & & & $-0.1472(-2.298)$ \\
\hline$\triangle \ln Y_{t-3}$ & & $0.2865(2.081)$ & \\
\hline$\triangle \ln U_{t-1}$ & & & $0.4401(2.464)$ \\
\hline$\triangle \ln U_{t-3}$ & & & $-0.4160(-2.423)$ \\
\hline$\triangle \ln U_{t-4}$ & $-0.8808(-2.057)$ & & \\
\hline$A d j-R^{2}$ & {$[0.2194]$} & {$[0.6098]$} & {$[0.4735]$} \\
\hline JB test & {$[0.7051]$} & {$[0.6901]$} & {$[0.0008]$} \\
\hline LM test & $\begin{array}{l}{[0.7998]} \\
{[0.4032]}\end{array}$ & $\begin{array}{l}{[0.2357]} \\
{[0.1150]}\end{array}$ & $\begin{array}{l}{[0.5516]} \\
{[0.7618]}\end{array}$ \\
\hline $\mathrm{ARCH}$ test & $\begin{array}{l}{[0.1432]} \\
{[0.3516]}\end{array}$ & $\begin{array}{l}{[0.1691]} \\
{[0.1337]}\end{array}$ & $\begin{array}{l}{[0.6887]} \\
{[0.6937]}\end{array}$ \\
\hline
\end{tabular}

TABLE III The Result of VECM between $\ln E, \ln Y$ and $\ln U$

Note: the figure in the parentheses is the $t$ value of coefficient, and the figure in brackets is accompanying probability $\mathrm{P}$ value. JB test is used to test the normality of residuals; LM test and ARCH test are respectively used to test the serial correlation and the heteroscedasticity of residuals, and their lag order numbers are both 1 and 2 .

The diagnostic results show that the fitting degree of the equation is generally better, the residuals have no significant phenomena of autocorrelation and heteroscedasticity, and except for $\Delta(\ln U)$, all of these meet the normal distribution and some other assumptions. In addition, in order to test the reliability of the final model set, recursive residual accumulation of each estimating equation and CUSUM are applied to test the parameter stability of model, the results show that the statistical volume is within plus or minus $5 \%$ of significantly level threshold, which indicates that the coefficient of the above error correction model is stable in sample period, therefore, it can be assumed that our estimation results are quite reliable.

It can be seen from Table III that the fluctuations of energy consumption are affected by itself and the fluctuations of urbanization level, and the fluctuations of economic growth have no effect on it in the short term. The regression coefficient of error correction items ECMt-1 hasn't passed the significance test, and it shows that in the short term, the longterm equilibrium relationship among energy consumption, urbanization and economic growth can hardly adjust the deviation of current energy consumption level from the equilibrium level, or energy consumption is the weakly exogenous variables about long-term parameters; the short- 
term changes in economic growth are only affected by itself and the energy consumption, and the urbanization level has no effect on it. It should be noted that the increase of the energy consumption level that lags for 3, 4 phases in the short term would restrain economic growth.

\section{Granger Causality Analysis}

By applying Granger causality test procedure of error correction model, Table 4 gives the Wald test results of the Granger causality between any two variables of energy consumption, urbanization level and economic growth in Shanghai City.

Table IV shows that for the energy consumption in Shanghai City, Shanghai's urbanization is the Granger reason for its energy consumption whether in the long term or in the short term, but economic growth cannot be the Granger reason for its energy consumption in neither long term nor short term; for the economic growth in Shanghai City, although energy consumption and urbanization in Shanghai City cannot be its short-term Granger reason, they are the Granger reason that causes the economic growth in Shanghai City in the long term; for the urbanization in Shanghai city, energy consumption is its short-term Granger reason but not long-term reason, and on the contrary, economic growth is not the Granger reason for urbanization in the short term, but it is the Granger reason for urbanization in the long run.

TABLE IV The Result of Granger Causality Test Based on VECM

\begin{tabular}{|c|c|c|c|}
\hline \multirow{2}{*}{$\begin{array}{c}\text { Explanatory } \\
\text { Variable }\end{array}$} & \multicolumn{3}{|c|}{ Dependent Variable } \\
\cline { 2 - 4 } & $\triangle \ln E$ & $\triangle \ln Y$ & $\triangle \ln U$ \\
\hline$\triangle \ln E$ & - & $7.296[0.121]$ & $8.125[0.087]$ \\
\hline$\triangle \ln Y$ & $2.8492[0.583]$ & - & $6.461[0.167]$ \\
\hline$\triangle \ln U$ & $10.549[0.032]$ & $2.136[0.711]$ & - \\
\hline$\triangle \ln E$ and ECM & - & $15.987[0.007]$ & $8.145[0.148]$ \\
\hline$\triangle \ln Y$ and ECM & $4.082[0.538]$ & - & $9.498[0.091]$ \\
\hline$\triangle \ln U$ and ECM & $10.649[0.059]$ & $12.919[0.024]$ & - \\
\hline
\end{tabular}

Note: $\chi^{2}$ is used to test statistical volume in the inspection process of above Granger causality, and the figure in brackets is accompanying probability $\mathrm{P}$ value.

\section{Conclusions}

Based on the annual data during 1978-2010 in Shanghai City, this paper studies the long-term equilibrium relationship, short-term dynamic relationship and Granger causality among Shanghai's urbanization level, economic growth and the whole society's energy consumption, and the following conclusions can be drawn from the results of the analysis:

(1) Although the urbanization progress, economic growth and energy consumption in Shanghai City are all integrated of order one I (1) sequence, there is a stable equilibrium relationship among them from the perspective of long term. There is a positive correlation between Shanghai's economic growth and urbanization and its energy consumption. But error correction model suggests that there are some differences between the short-term relationship and the long-term equilibrium relationship among Shanghai's urbanization level, economic growth and energy consumption, these three elements are in the positive correlation in the long term, but not in the short term, therefore, according to this point, some relevant departments should take a strategic height and at the same time should take the short-term effects into account.

(2) Shanghai's urbanization and its economic growth have no Granger causality in any direction in the short term, but they are the Granger reason of each other in the long term. The possible reason is that the index of "the proportion of urban population in the whole population" is applied to measure the urbanization level, but China's urban population statistics is from the household registration, and the urban-rural dual structure and the household registration system of urban-rural split which were formed in the planned economy period of China haven't been really broken up because of historical reasons, therefore, the urbanization level of population is largely constrained by relevant policies and systems and is less vulnerable to the impact of economic development, and at the same time the promotion of population urbanization can hardly promote economic development effectively in the short term. Therefore, the relevant government departments should accelerate the reform of household registration system, in order to achieve a better positive dynamic relationship of the mutual promotion and the reciprocal causation between economic growth and urbanization.

(3) Shanghai's economic development cannot be the Granger reason for energy consumption in either long term or short term, but energy consumption is the factor for economic growth in the long term. It can be seen that Shanghai's economic development cannot do without the input of energy. Therefore, in the promotion process of the population urbanization in Shanghai City, the measures like the adjustment of industrial structure, the transformation of economic growth method and so on should be taken to solve the energy constraint dilemma, so as to achieve its sustainable development.

\section{References}

[1] C.B.L. Jumbe, "Cointegration and causality between electricity consumption and GDP : empirical evidence from Malawi," Energy Economics, vol. 26, no. 1, pp. 61-68, 2004

[2] K.N. Paresh and S. Russell, "Electricity Consumption, employment and Real Income in Australia Evidence from Multivariate Granger Causality Tests," Energy Policy, vol.33, no.9, pp.1109-1116, 2005.

[3] B.Q. Lin, "Electricity consumption and economic growth in China: based on production function," Management World, no.11, pp.18-27, 2003, in China.

[4] Z.F. Tan, P.J. Xie, and J.C. Hou, "Study on Energy Demand Model Considering Structural Break in China," Technology Economics, vol.27, no.10, pp.56-68, 2008, in China.

[5] Y.B. Liu, “An Analysis of Dynamic Econometric Relationship between Development of Urbanization and Growth of Energy Consumption in China," Journal of Finance and Economics, vol.33, no.11, pp.72-81, 2007 , in China.

[6] X.P. He, X.Y. Liu, and Y.P. Lin, "China's electricity demand forecast under urbanization process," Economic Research Journal, no.1, pp.118130, 2009, in China..

[7] P.J. Xie, Z.F. Tan, J.C. Hou, and M.B. Wang, "Analysis on dynamic relationship between urbanization and electricity consumption level in China," Power system Technology, vol.33, no.14, pp. 72-77, 2009, in China. 